Document downloaded from:

http://hdl.handle.net/10251/115877

This paper must be cited as:

Seguí Gil, L.; Fito Maupoey, P. (2018). An integrated approach for pineapple waste valorisation. Bioethanol production and bromelain extraction from pineapple residues. Journal of Cleaner Production. 172:1224-1231. doi:https://doi.org/10.1016/j.jclepro.2017.10.284

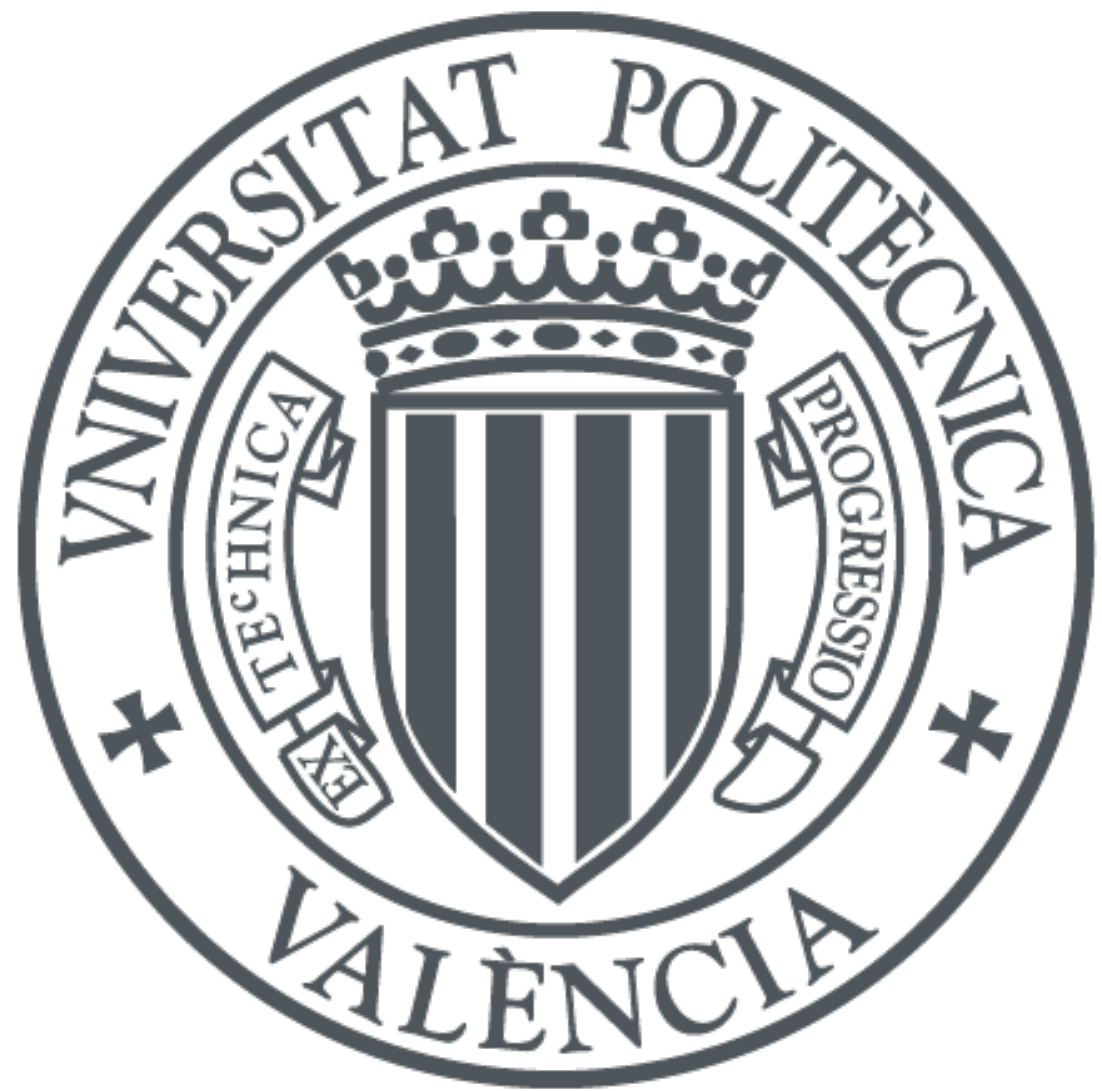

The final publication is available at

https://doi.org/10.1016/j.jclepro.2017.10.284

Copyright Elsevier

Additional Information 
Word count: 5929

\title{
AN INTEGRATED APPROACH FOR PINEAPPLE WASTE VALORISATION. BIOETHANOL PRODUCTION AND BROMELAIN EXTRACTION FROM PINEAPPLE RESIDUES.
}

Lucía Seguí Gil, Pedro Fito Maupoey

Instituto Universitario de Ingeniería de Alimentos para el Desarrollo (IUIAD), Universitat Politècnica de València, camino de Vera s/n, C.P. 46822, Valencia, Spain.

email: lusegil@upvnet.upv.es

Tel. 0034963877000 (Ext.73676)

orcid.org/0000-0002-2711-9445

\begin{abstract}
Waste management is critical for the food industry for which there is increasing interest in food waste valorization processes. In the present work, some integrated approaches for pineapple waste valorisation that combine the production of bioethanol and bromelain in a unique process are suggested. Proposals are based in the optimization of bioethanol production through different fermentation and saccharification processes: direct fermentation of the liquor, consecutive saccharification and fermentation of the solid waste and simultaneous saccharification and fermentation of the solid waste. To this end, performance of three different industrial yeasts has been assayed (Saccharomyces bayanus CECT 1926, Saccharomyces cerevisiae CECT 11020 and Saccharomyces cerevisiae CECT 1319). Results indicated that simultaneous saccharification and fermentation increases ethanol production $(5.4 \pm 0.1 \% \mathrm{v} / \mathrm{v})$ as compared to direct fermentation $(4.7 \pm 0.3 \%)$ and consecutive saccharification and fermentation $(4.9 \pm 0.4 \% \mathrm{v} / \mathrm{v})$. On the other hand, bromelain separation has been accomplished using membrane separation techniques (microfiltration and ultrafiltration), and further stabilization by freeze-drying. An increased protein concentration after downstream processes have been confirmed by the Lowry analytical method $(11.5 \pm 1.2$ to $21.0 \pm 1.3 \mathrm{mg} / \mathrm{mL}$ in the retentate), and the proteolytic activity of the lyophilised powder has been estimated in 340-805 GDU (Gelatine Digestion Units). Permeate has successfully undergone fermentation for bioethanol production.
\end{abstract}




\section{Keywords}

Pineapple waste, valorisation, bioethanol, saccharification, bromelain, membrane separation.

\section{Introduction}

Waste disposal is one of the major problems facing most food processing plants (Goula and Lazarides 2015). Fruit and vegetables processing for the production of juice or canned food, among others, yields a large amount of industrial residues that are often infra-utilized as feed or as fertilizer. In fact, agricultural uses of these wastes are no longer considered a feasible alternative (Goula and Lazarides, 2015). In addition, demand of these products as a feed may vary and is dependent on agricultural yields, for which efficient, inexpensive and environmentally friendly use of these materials has become more and more important (Schieber et al. 2001). According to Oreopoulou and Russ (2007), there is increasing interest in the valorization of the wastes generated by the food industry, also as a consequence of the new developments in process engineering and the resulting byproducts. Waste utilization in the fruit and vegetable processing industry is an important challenge that governments must address towards sustainability (Roda et al. 2016).

In particular, pineapple industrialization is known to generate a significant amount of solid residues and values as high as 75-80\% have been reported (Abdullah and Mat 2008; Roda et al. 2016). Pineapple industrial waste is found to have potential uses as a raw material for obtaining value-added products since it contains simple and complex sugars that may be used in fermentation for the production different metabolites such as ethanol, citric acid or vinegar (Imandi et al. 2008; Kumar et al. 2003; Nigam, 2000; Roda et al. 2016; Tanaka et al. 1999), and it can also be a source for other bioactive compounds such as antioxidants (Ketnawa et al. 2012). In addition, pineapple residues might also contain the proteolitic enzyme bromelain, commonly obtained from the stem (EC 3.4.22.33), but also present in the mature fruit (Ketnawa et al. 2012; Lozano de González et al. 1993).

Bioethanol can be produced from different raw materials which are commonly classified into three categories: sucrose-containing feedstocks (sugar cane, sugar beet, sweet sorghum), starch materials (corn, potatoes, wheat) and lignocellulosic materials (wood, grasses). One major problem with bioethanol is the availability of raw materials for the production, along with their price having a big impact on the production costs. Present research is mainly focused on lignocellulosic biomass (Balat, 2011; Limayem et al. 2012), this being considered the most promising feedstock due to availability and low cost, although a successfully effective conversion of lignocellulosic materials into bioethanol is still limited due to 
lignocellulose complexity. Pineapple waste is a material rich in simple sugars and complex carbohydrates such as cellulose and hemicellulose that are potentially hydrolysable into fermentable sugars. Nevertheless, the residue needs to be pretreated and saccharified before fermentation in order to increase the yield and make large-scale production feasible (Conesa et al. 2016a). On the other hand, the use of the pineapple wastes as a source of proteolitic enzymes could represent an interesting alternative. Bromelain and other cysteine proteases are well known enzymes that have been identified in different parts of the pineapple plant. Bromelain is broadly employed in the pharmaceutical and food industries, as well as used in the cosmetics, textile, leather and detergents industries (Ketnawa et al. 2012; Schieber et al. 2001).

As reported by Goula and Lazarides (2016), integrated processes can turn industrial food waste into valuable by-products and/or ingredients. In this line, the present work focuses on the valorisation of industrial pineapple waste coming from the juice and canning industries, by obtaining bioethanol and bromelain, and thus offering an alternative to present uses. The study aims to discuss the feasibility of producing bioethanol and bromelain from industrial pineapple waste, in separated processes as well as in an integrated one. In a first approach, three different processes for obtaining bioethanol from pineapple waste are assayed: direct fermentation (DF) of the liquor extracted from the solid waste, consecutive saccharification and fermentation (CSF) of the blended solid waste, and simultaneous saccharification and fermentation (SSF) of the blended solid waste. Then, new stages are incorporated to the process in order to separate one more valuable product from the same waste material: bromelain. Centrifugation and membrane separation techniques (microfiltration and ultrafiltration) are proposed as an alternative to enzyme precipitation with organic solvents or salts. Both microfiltration and ultrafiltration are pressure-driven membrane technologies used in for protein separation and purification (Saxena et al, 2009). Microfiltration membranes are especially well suited for the separation of fine particles in range of $0.1-10.0 \mu \mathrm{m}$, whereas ultrafiltration membranes are designed to provide high retention of proteins and other macromolecules. Protein concentration by membrane separation processes will allow to obtain a protein concentrated stream, and a medium suitable for further fermentation.

\section{Materials and methods.}

\subsection{Pineapple waste separation and characterization.}

Golden Sweet pineapples (Ananas comosus [L.] Merr., MD-2 cv.) were used in the experiments. Pineapple waste (core and peel) was separated using a pineapple cutter, and 
grinded in a blender in order to obtain the solid pineapple waste. This solid pineapple waste was used in the saccharification and fermentation processes as explained later. Other processes required the liquid phase, for which the solid waste was mixed with a $0.1 \mathrm{~N}$ $\mathrm{Ca}(\mathrm{OH})_{2}$ solution in order to maximize liquid phase separation and pressed in pilot plant scale pneumatic equipment $\left(2.5 \mathrm{~kg} / \mathrm{m}^{2}\right)$. Different $\mathrm{Ca}(\mathrm{OH})_{2}$ concentrations were assayed $(0$, 0.1, 0.2, 0.3, 0.4 y 0.5\% w/w). Pressing yielded a liquid phase (liquor) and a press cake. Waste and liquor yields ( $\mathrm{Y}_{\text {waste, }}, \mathrm{Y}_{\text {liquor }}$ ) were calculated by weighing the mass of six batches (9 pineapples each) before and after each stage, in triplicate (equations 1 and 2). Solid waste, liquor and cake were characterized in terms of total soluble solids (TSS), fermentable sugars (sucrose, glucose and fructose), $\mathrm{pH}$, water $\left(\mathrm{x}_{\mathrm{w}}\right)$ and protein $\left(\mathrm{x}_{\mathrm{P}}\right)$ contents, using the analytical procedures given below.

$$
\begin{aligned}
& Y_{\text {waste }}=\frac{M_{\text {waste }}}{M_{\text {pineapple }}} \\
& Y_{\text {liquor }}=\frac{M_{\text {liquor }}}{M_{\text {waste }}}
\end{aligned}
$$

\subsection{Saccharification and fermentation processes for bioethanol production: direct} fermentation (DF), consecutive saccharification and fermentation (CSF), and simultaneous saccharification and fermentation (SSF).

Three different processes were applied in order to obtain bioethanol from the pineapple waste: direct fermentation of the extracted liquor (DF), consecutive saccharification and fermentation of the solid waste (CSF), and simultaneous saccharification and fermentation of the solid waste (SSF). Hydrolysis of the cellulosic materials was performed adding Aspergillus niger cellulase and hemicellulase $(1 \mathrm{~g} / \mathrm{kg} \times 1.2$ $\mathrm{U} / \mathrm{g}$ hemicellulase and $6 \mathrm{~g} / \mathrm{kg} \times 0.87 \mathrm{U} / \mathrm{g}$ cellulose, Sigma-Aldrich, Spain), and it was either performed consecutively (CSF) or simultaneously (SSF) to fermentation. Preliminary tests were used to settle conditions for saccharification and fermentation processes. saccharification with cellulase and hemicellulase was tested at $28{ }^{\circ} \mathrm{C}$ (closer to optimum temperature for yeasts) and $40{ }^{\circ} \mathrm{C}$ (approximate optimum temperature for the enzymes, according to specifications), during 26 hours, at different $\mathrm{pH}$ (4, 5 and 6), in an incubation oven (PSelecta, model Incudigt). On the other hand, fermentation experiments (DF and SSF) were performed at $\mathrm{pH} \mathrm{4,} 5$ and 6 at $28{ }^{\circ} \mathrm{C}$, during 72 hours, in $100 \mathrm{~mL}$ flasks containing 75 $\mathrm{mL}$ (or g) of liquor (or solid waste, as appropriate). Three different industrial yeasts obtained 
from the CECT collection (Colección Española de Cultivos Tipo) were used in the fermentation experiments: Saccharomyces bayanus 1926, Saccharomyces cerevisiae 11020 and Saccharomyces cerevisiae 1319. Total soluble solids (TSS), fermentable sugars content (sucrose, glucose and fructose) and colony forming units (CFU) were determined before and after fermentation, according to the methods described below. Alcoholic content was measured after fermentation (48 and $72 \mathrm{~h}$ ) by means of an enzymatic test kit (R-Biopharm), as explained later. In order to evaluate the need for sterilizing the medium, tests were

performed on sterilized and non-sterilized liquor. Sterilization consisted of introducing the flasks containing the fermentation medium in autoclave at $120{ }^{\circ} \mathrm{C}$ during $5 \mathrm{~min}$. Thermal treatment was assayed in order to prevent spoilage by microorganisms different from yeasts (mainly acetic bacteria); in addition, in the case of the solid waste, thermal treatment could contribute as a lignocellulose pretreatment, and make cellulose and hemicellulose more accessible to enzymes (Roda et al. 2016). All experiments were performed in triplicate.

\subsection{Downstream processes for enzyme separation. Concentration and stabilization.}

Membrane separation techniques were proposed as an alternative to enzyme precipitation with organic solvents or salts, in order to obtain a medium suitable for subsequent fermentation. In order to choose the filters and membranes needed for enzyme separation, particle size distribution was determined by using Malvern Mastersizer equipment (Malvern Instruments Ltd, U.K.) as detailed later.

\subsubsection{Conditions for centrifugation, microfiltration and ultrafiltration.}

In order to reduce the volume of suspension particles and proceed with ultrafiltration, the following procedure was established: (i) coarse particles were separated by centrifugation (P. Selecta Medifriger) at 10,000 during $10 \mathrm{~min}$. Then the supernatant was subjected to a twostep vacuum-depth microfiltration procedure: (ii) $1.2 \mu \mathrm{m}$ glass fibre filter, followed by (iii) $0.2 \mu \mathrm{m}$ cellulose acetate filter. (iv) Proteins were then concentrated by ultrafiltration with 10,000 kDa Amicon Ultra-15 Centrifugal Filter Units (Millipore ${ }^{\circledR}$ ), in an oscillating rotor type centrifuge (P. Selecta Medifriger), at maximum speed during $20 \mathrm{~min}$. This allowed to recover a concentrated stream or retentate rich in proteins, and a permeate free of them.

\subsubsection{Stabilization by freeze drying.}

Some industrial enzymes are commercialized in their soluble form since enzymes are stable at high concentrations; in other cases, enzymes are commercialized after dehydration. Freeze drying or lyophilisation is a common stabilizing technique for biological materials 
since the conditions of the process (low processing temperature and vacuum) helps preserve bioactivity (Karam et al. 2016). In order to obtain a dehydrated enzymatic preparation, the retentate was collected and introduced in Petri dishes (10 g), frozen at $-22{ }^{\circ} \mathrm{C}$ during $24 \mathrm{~h}$, and subsequently subjected to a freeze drying operation in a Lioalfa-6 (Telstar) lyophiliser (operating conditions: $-50^{\circ} \mathrm{C}, 0.98 \mathrm{mbar}, 24 \mathrm{~h}$ ).

\subsubsection{Fermentation of permeate}

In an integrated approach for the valorization of the pineapple waste, bromelain could be obtained from the retentate, whereas the permeate, free of enzymes, contain sugars that could be subjected to further fermentation. In order to evaluate the introduction of this new stage in the valorization process, fermentation of the permeate (PF) was performed and results compared to direct fermentation of the liquor obtained from the pressed waste (DF). To this purpose, the industrial yeast Saccharomyces bayanus CECT 1926 was chosen, and process conditions were $\mathrm{pH} \mathrm{5,} 28{ }^{\circ} \mathrm{C}, 72$ hours. Experiments were performed in triplicate. Fermentable sugars content (sucrose, glucose and fructose), total soluble solids (TSS) and CFU were determined before and after fermentation, as explained in the analytical determinations section. Finally, alcoholic content was measured after fermentation (72 h).

\subsection{Analytical determinations.}

The following analytical methods were used to characterize the streams, as explained in the corresponding sections. All analytical determinations were performed, at least, in triplicate.

\subsubsection{Total soluble solids, $\mathrm{pH}$ and moisture content $\left(x_{w}\right)$.}

Total soluble solids (TSS) were estimated by refractrometry (Atago NAR-3T refractometer) obtaining the Brix degrees ( ${ }^{\circ}$ Brix) values. A digital pH-meter (Mettler Toledo) was used for $\mathrm{pH}$ determinations. The moisture content $\left(\mathrm{x}_{\mathrm{w}}\right)$ was determined by the 20.013 AOAC gravimetric method (AOAC, 1980).

\subsubsection{Fermentable sugars (glucose, fructose and sucrose).}

The amount of glucose, fructose and sucrose present in the samples was identified and quantified by High-Performance Anion-Exchange Cromatography with a Pulsed Amperometric Detector (HPAEC-PAD), using a Metrohm IC chromatograph system equipped with a 716 Compact module and an ICnet 2.0 software program for interpreting the results. A three-step PAD setting was used with the following path intervals (ms) and 
potentials (V): $\mathrm{t}_{1}: 400 / \mathrm{E}_{1}=+0.05$ (detection); $\mathrm{t}_{2}: 200 / \mathrm{E}_{2}=+0.75$ (cleaning); $\mathrm{t}_{3}: 400 / \mathrm{E}_{3}=-0.15$ (regeneration). Metrosep Carb 1 250/4.6 column (250 mml x $4.6 \mathrm{mmID}$ ) was used coupled to a guard column. Analyses were conducted at $32{ }^{\circ} \mathrm{C}$, 8.8 MPa, injection volume: $20 \mu \mathrm{L}$ and sodium hydroxide $0.1 \mathrm{M}$ was used as the mobile phase $(1 \mathrm{~mL} / \mathrm{min})$. Before measurements, the liquid was filtrated ( $0.45 \mu \mathrm{m}$ nylon filter) and dilution as required. High-purity standards (Sigma-Aldrich Química SL, Tres Cantos, Madrid, Spain; purity $\geq 99 \%$ ) of glucose, fructose, and sucrose were used to prepare standard calibration curves. All the determinations were carried out in triplicate.

\subsubsection{Protein content.}

The Lowry method (Lowry et al. 1951) was used to estimate the protein content of the different streams involved in the downstream processes for enzyme concentration. This is a classical colorimetric method for protein determination in which the Folin-Cicolteau reagent reacts with unfolded proteins, previously treated with a $\mathrm{CuSO}_{4}$ solution. Protein concentration was calculated thanks to a standard BSA (Bovine Serum Albumin, SigmaAldrich, Spain) curve. This method has been previously used to calculate bromelain concentration in pineapple samples (Krishnan and Gokulakrishnan, 2015; Gautam et al. 2010).

\subsubsection{Colony Forming Units (CFU).}

CFU were determined by the serial dilution method, by serially diluting in 5 tubes containing $9 \mathrm{~mL}$ of a $0.9 \% \mathrm{NaCl}$ solution. Then, $0.1 \mathrm{~mL}$ were plated in YPD-agar medium in order to obtain the $10^{-4}, 10^{-5}$ and $10^{-6}$ dilutions. Counting was done after $48 \mathrm{~h}$ incubation at 28 ${ }^{\circ} \mathrm{C}$, on plates containing 30 to $300 \mathrm{CFU}$.

\subsubsection{Alcoholic content (\%).}

Ethanol content (\%) in the fermented medium (liquor or solid waste) was determined by means of enzymatic test kit (ethanol UV-method, R-Biopharm). The kit is based in various spectrophotometric measurements performed on a dilution of the sample $(1: 1000 \mathrm{v} / \mathrm{v}$ in bidistilled water), after reacting with the enzymes provided in the kit. Measurements are performed at $340 \mathrm{~nm}$ and the ethanol percentage calculated by the relationship given in the kit specifications.

\subsubsection{Particle size.}

Particle size distribution was determined by using Malvern Mastersizer equipment (Model 2000; Malvern Instruments Limited, Worcestershire, U.K.) with a short-wavelength 
blue light source in conjunction with forward and backscatter detection to enhance sizing performance in the range $0.02-2000 \mu \mathrm{m}$. Measurements were performed applying ultrasounds and a stirring speed of 1500-2000 rpm.

\subsubsection{Enzyme activity (Gelatin Digestion Unit, GDU).}

Proteolitic activity of the concentrated extract was determined by the Gelatin Digestion Unit method (Enzyme Development Corporation) (Krishnan and Gokulakrishnan, 2015; Gautam et al., 2010). The Gelatin Digestion Unit was calculated as the amount of enzyme (extract) able to release $1 \mathrm{mg}$ of amino nitrogen from a standard gelatin digestion, at $\mathrm{pH} 4.5$ after 20 min of digestion at $45{ }^{\circ} \mathrm{C}$, using the titration method described by Moodie (2001). The gelatin substrate was prepared by dissolving $25 \mathrm{~g}$ of gelatin (bacteriologic gelatin Cultimed, Panreac) in $375 \mathrm{~mL}$ of water, brought to a boil, cooled down to $45^{\circ} \mathrm{C}$, pH-adjusted to $4.5(\mathrm{HCl} 0.1 \mathrm{~N})$ and bring up to $500 \mathrm{~mL}$ in distilled water. The lyophilized enzyme was compared to a reference material (stem bromelain (EC 3.4.22.33); Sigma-Aldrich, Spain).

\subsection{Statistical analyses.}

Statgraphics Centurion XVI® was used for statistical analyses. Statistically significant differences at the $95 \%$ confidence level were determined by the one way or multifactor ANOVAs, as required.

\section{RESULTS AND DISCUSSION}

\subsection{Industrial pineapple waste. Characterization and yields.}

Six batches of nine fruits each were analyzed in order to characterize the pineapple solid waste and calculate the corresponding yields. The amount of waste represented more than fifty percent of the original material $(51.6 \pm 0.2 \% \mathrm{w} / \mathrm{w})$. Characterization of the grinded pineapple waste is given in Table 1. Results were found to be consistent with the published in the literature (Ban-koffi et al. 1990; Ketnawa et al. 2012; Nigam, 2000; Roda et al. 2016), although not always directly comparable since some investigations are performed on the whole fruit or correspond to a diluted extract. The amount of fermentable sugars was considered sufficient for undergoing fermentation, and protein concentration suggested the presence of the expected proteolytic enzymes. After pressing, more than $60 \%(\mathrm{w} / \mathrm{w})$ of the grounded waste could be separated as a liquor; this was maximized to $68.4 \pm 0.8 \%$ with the addition of $0.1 \% \mathrm{Ca}(\mathrm{OH})_{2}$, which corresponded to $35 \%$ of the pineapple fruit.

\subsection{Saccharification and fermentation processes for bioethanol production.}


Preliminary studies were undertaken to determine optimum conditions for fermentation and saccharification of pineapple waste. The amount of sugars yielded during the enzymatic hydrolysis was completely stabilized after 24 hours and, as expected, the highest temperature $\left(40{ }^{\circ} \mathrm{C}\right)$ yielded more fermentable sugars. As for $\mathrm{pH}$, TSS increased more significantly when

$\mathrm{pH}$ was adjusted to 6 . Therefore, a 24 hours saccharification step, at $\mathrm{pH} 6$ and $40{ }^{\circ} \mathrm{C}$ was settled for the consecutive saccharification and fermentation (CSF) process.

As for fermentation, the appropriateness of performing a thermal treatment before fermentation was evaluated and confirmed since acetic bacteria developed in the nonsterilized media between 48-72 hours of fermentation. As for $\mathrm{pH}$, fermentation was tested in the range 4 to 5 (figure 1) for the three strains assayed. Sacharomyces bayanus CECT 1926 gave the best results in the whole range, this being statistically significant at $\mathrm{pH} 4$. All yeasts assayed performed better at $\mathrm{pH} 5$ and, once adopted this conditions as optimal for fermentation ( $28{ }^{\circ} \mathrm{C}, \mathrm{pH} \mathrm{5,} 72 \mathrm{~h}$ ), differences among yeasts were not statistically significant. For the simultaneous saccharification and fermentation (SSF) process, the appropriate temperature for yeasts $\left(28^{\circ} \mathrm{C}\right)$ was preferred against the optimum temperature of the enzymes $\left(40^{\circ} \mathrm{C}\right)$, whereas the enzymatic load was maintained and similar to that of CSF.

\subsubsection{Comparison between direct fermentation (DF) and saccharification-fermentation} experiments (CCF, SSF).

In figure 2, the evolution of TSS, CFU and $\mathrm{pH}$ during the three different processes assayed are shown, together with the final concentration of ethanol yielded after $72 \mathrm{~h}$ of fermentation. The amount of CFU inoculated to the medium was similar in all cases. The increase in the CFU counting indicates a good adaptation of the yeast to the fermentation medium. During the first $48 \mathrm{~h}$ of fermentation, a decrease in the TSS content is observed in parallel to microorganism growth; then, in the following 24 hours, microorganism growth rate diminishes due to nutrients depletion. In the CSF process, the saccharification stage increased TSS significantly; when fermentation begins, evolution of the Brix degrees followed a similar pattern to that of the DF process. Nevertheless, in spite of the increase in the TSS content available for fermentation, ethanol yield was similar to the previous case. As compared to DF, CSF was characterized by a more moderated microorganism growth and TSS depletion during the first $24 \mathrm{~h}$ of fermentation. This could be attributed to the higher sugar concentration in the medium, as some organisms such as S. cerevisiae decrease their activity when there is an excess of substrate (Owen, 1991). A similar behavior regarding CFU and TSS evolution was observed in the SSF process but, in contrast, performing SSF did 
significantly increase the ethanol yield. In fact, SSF has been claimed to increase the ethanol yield due to the progressive transformation of sugars into ethanol in the coupled process of fermenting while obtaining simple sugars from cellulose and hemicellulose hydrolysis, thus reducing inhibition of yeasts activity due to an excess of glucose (Sánchez and Cardona, 2008). As for $\mathrm{pH}$, both saccharification and fermentation processes reduce the $\mathrm{pH}$ values of the medium due to the different species released to it, simple sugars during hydrolysis, and organic acids during fermentation. The graphs shown correspond to the yeast Saccharomyces bayanus 1926, since no significant differences in the evolution of UFC, TSS and pH were found among the different yeasts assayed.

In table 2, performance of the three yeasts assayed regarding ethanol production is summarized. First row indicates the initial amount of fermentable sugars present in the waste material; next, the sugar content (sum of glucose, fructose and sucrose obtained by ion exchange chromatography) after the different processes applied is indicated; and finally, the ethanol yield is shown. Ethanol yield was calculated as the amount of ethanol produced with respect to the sugar consumed, in glucose units (gethanol/gglucose). It was confirmed that CSF did not improve the ethanol yield, as compared to the DF process; in contrast, SSF improved the yield by $12-15 \%$. Fermentable sugars were completely consumed during DF; however, a residual amount of simple sugars was present at the end of fermentation when saccharification was applied, either consecutively or simultaneously. This could be due to the residual action of hydrolytic enzymes still present in the medium. Differences among yeasts were not significant, as deduced from the ANOVA analysis.

\subsection{Enzyme concentration by membrane separation techniques.}

The effect of centrifugation on particle size distribution is shown in figure 3 , where line A represents the liquor after the press stage and line B the liquor after centrifugation at 10,000 during $10 \mathrm{~min}$. Particle size distribution indicates the volume (\%) of particles of a specific size being measured. The centrifuged liquor shows a larger volume of smaller particles which indicates the efficiency of centrifugation. Equivalent diameters (d) in percentiles 0.1, 0.5 and 0.9 confirm the separation of coarser particles during centrifugation. Particle size analysis was also used to decide the filters to be used in the microfiltration stages. Since the smaller particles detected were slightly above $1 \mu \mathrm{m}$, a two-stage microfiltration process was established: first microfiltration across a coarser filter $(1.2 \mu \mathrm{m})$ followed by microfiltratoin through a $0.2 \mu \mathrm{m}$ filter were performed in order to eliminate suspended particles and proceed 
with ultrafiltration. Ultrafiltration was performed in order to concentrate the enzyme, using $10 \mathrm{kDa}$ membranes, considering the estimated size of bromelain and related enzymes $(\sim 28$ $\mathrm{kDa}$ ) (Ketnawa et al. 2012). The impact of downstream processes on enzyme concentration was evaluated by determining the protein content (Lowry et al. 1951) after each stage (Figure 4). As shown, centrifugation and microfiltration did not have a significant effect on protein concentration, whereas ultrafiltration doubled protein content. Microfiltration yields were $98 \pm 9 \%(\mathrm{w} / \mathrm{w})$ and $96 \pm 3 \%(\mathrm{w} / \mathrm{w})$ for the first and second microfiltration stages, respectively; whereas the recovery index of the ultrafiltration step $\left(\mathrm{M}_{\text {retentate }} / \mathrm{M}_{\mathrm{feed}} \times 100\right)$ was calculated as $53 \pm 1 \%$.

\subsubsection{Proteolitic activity of the freeze-dried enzymatic preparation.}

After ultrafiltration, the concentrate was subjected to freeze drying in order to obtain a dried enzymatic preparation. Proteolitic activity was determined on the freeze-dried product, and compared to that of a reference lyophilized material (stem bromelain) as explained in the materials and methods section. Proteolitic activity of the freezed-dried preparation was estimated in 340-805 GDU, indicating the successful concentration of proteolytic enzymes in the liquor separated from pineapple waste. The proteolytic activity of the lyophilized powder was lower than that of the reference material (stem bromelain) which was in the range 14002800 GDU. Significant differences between both dried enzymes could be due to the different origin and form of the enzymes that may be present in the pineapple plant (Ketnawa et al. 2012), since the activity of stem bromelain is higher than the activity of fruit bromelain. Nevertheless, the proteolytic activity of the enzyme obtained in this work is in the range of some commercial bromelain powders, as checked for some commercially available products. It should be pointed out, however, that caking of the lyophilized powder was evidenced after some days of storage, probably due to the presence of highly hygroscopic components, such

as sugars. Therefore, optimization of the freeze-drying stage by the addition of some excipient such as maltodextrin is suggested at this point (Ratti, 2013).

\subsubsection{Fermentation of permeate after ultrafiltration.}

The permeate obtained after ultrafiltration was further subjected to fermentation by the industrial yeast Saccharomyces bayanus CECT 1926. Results are given in table 3. Fermentable sugars (glucose, fructose and sucrose) were not registered in the chromatograms after fermentation, indicating the consumption of all sugars present in the medium, which 
was also evidenced by a TSS decrease. Permeate fermentation yielded a medium richer in ethanol as compared to fermentation of the original liquor. Decreasing the concentration of the proteolytic enzyme bromelain in the fermentation medium could have had a beneficial effect on yeasts activity. Hence, production of bioethanol after bromelain separation was successfully achieved.

\subsection{Integrated processes for pineapple waste valorization.}

The results obtained in the present work suggest that both value-added products, bioethanol and bromelain, may be obtained from industrial pineapple waste. In a first approach, fermentation and saccharification processes on either the liquid or solid phases have been studied. Best results have been obtained when performing SSF on the solid waste, for which this process is preferred if bioethanol production wants to be maximized. In a second one, proteolytic enzymes (from retentate) and bioethanol (from permeate) have both been obtained from the pressed liquor, after membrane separation processes. In this second approach, the resulting press cake is still an option for agricultural purposes or animal feed, and it also could be a source for the extraction of other bioactive molecules such as antioxidants (Ketnawa et al. 2012). The press cake could alternatively be reintroduced in the process in order so as to undergo SSF, either directly or reconstituted with the permeate after UF, thus maximizing sugars profitability for bioethanol production. The residual biomass would have similar uses than the previously attributed to the press cake. Separation of the liquid phase and further reconstitution of the solid phase is a step also used to avoid sugar degradation during lignocellulose pretreatment, when high temperatures and/or long pretreatments are applied to increase saccharification efficiency. In particular, liquor separation of the solid waste has been applied in our investigations on microwave-assisted pre-treatments for an enhanced saccharification of lignocellulosic pineapple waste biomass in order to avoid sugar degradation and inhibitory compounds production (furfural, hydroxymethylfurfural) during microwave pretreatments (Conesa et al. 2016a,b).

Therefore, the proposed integrated processes for pineapple waste valorisation are summarized in figure 5. In the diagram shown, the different alternatives are identified with the word (or) and a different pattern of the arrows (full or different striped pattern). The mass of the main streams are also given in the diagram, which have been calculated taking into account the yields of each stage, and mass balances considering $1000 \mathrm{~kg}$ of processed pineapples (approximately $516 \mathrm{~kg}$ of residual biomass). A first alternative consists of separating the liquid (liquor) and solid (cake) phases in order to separate the enzymes from 
retentate, and bioethanol from permeate. $516 \mathrm{~kg}$ of pineapple waste would result in $169 \mathrm{~kg}$ of crude proteolytic preparation or $18 \mathrm{~kg}$ of dried enzymatic preparation with an activity of 340805 GDU, and 7-11 kg of dehydrated bioethanol (> 99.5\% v/v). The residual press cake (163 $\mathrm{kg}$ ) could be redirected to other purposes (animal feed, fertilizer or extraction of other bioactive compounds). Alternatively, the cake could undergo SSF for complex carbohydrates conversion into simple sugars (by means of the hydrolytic enzymes cellulase and hemicellulase), and simultaneous bioethanol production. The third integrated process proposed consists of using the permeate to reconstitute the press cake before SSF, in order to maximize sugar transformation into bioethanol. In both cases, after bioethanol recovery (usually by pressing/filtering, distillation and dehydration), the remaining biomass could be redirected to animal feed, fertilizer or extraction of bioactive compounds.

\section{CONCLUSIONS}

Waste management is an issue of increasing importance for the food industry that needs immediate action. Pineapple waste, an abundant agro-industrial residue, has been studied as a low-cost material for the generation of value-added products. Bioethanol and proteolytic enzymes have both been successfully obtained from industrial pineapple waste. Regarding bioethanol production, conditions for fermentation and saccharification processes have been evaluated and established ( $\mathrm{pH}$, temperature, time, thermal treatment). The three industrial yeasts haves shown a good adaptation to the medium, and performed similarly in the conditions adopted for fermentation ( $\mathrm{pH} \mathrm{5,} 28^{\circ} \mathrm{C}, 72 \mathrm{~h}$ ). SSF has resulted in an increased sugars conversion into ethanol, providing better ethanol yield than DF or CSF processes. Nevertheless, in order to select one or other process, it should be considered whether this improvement is sufficient to afford the cost of the enzymes.

Production of bioethanol from pineapple waste, either from the solid or liquid phase, would represent the partial valorisation of this food industry residues, but an integrated approach requires producing more value-added products. In this case, a proteolytic concentrated preparation has been obtained from the liquid phase of the pineapple residue, after applying centrifugation and membrane separation processes including microfiltration and ultrafiltration. Extraction of the enzyme has been accomplished directly from the liquid phase, with no additional water or other solvent for extraction. The lyophilized enzymatic preparation obtained has similar proteolytic activity than some commercial preparations; nevertheless, quality of freeze-dried product could be improved by the addition of some excipient such as maltodextrin. Bromelain has several potential commercial uses, mainly in 
the food and pharmaceutical industries, for which it represents an important contribution to the valorisation approach. The use of membrane separation techniques instead of protein precipitation with organic solvents or salts has allowed further permeate fermentation. To this end, permeate could be directly fermented o reintroduced in the process for a SSF stage. Although pilot plant studies are still needed to optimize separation parameters, the present work has succeeded in obtaining both value-added products from the same waste material, and determining the best conditions and process for bioethanol production. Accordingly, several proposals for an integrated pineapple waste valorisation process have been suggested.

\section{REFERENCES}

Abdullah, M.B., \& Mat, H. (2008). Characterisation of solid and liquid pineapple waste. Reaktor, 12(1), 48-52.

AOAC, 1980. Official Methods of Analysis. Association of Official Analytical Chemist, Washington, D.C.

Balat, M. (2011). Production of bioethanol from lignocellulosic materials via the biochemical pathway: A review. Energy Conversion and Management, 52(2), 858-875.

Ban-koffi, L., \& Han, Y.W. (1990). Alcohol production from pineapple waste. World Journal of Microbiology and Biotechnology, 6, 281-284.

Conesa, C., Seguí, L., Laguarda-Miró, N., \& Fito, P. (2016a). Microwaves as a pretreatment for enhancing enzymatic hydrolysis of pineapple industrial waste for bioethanol production. Food and bioproducts processing, 100, 203-213.

Conesa, C., Seguí, L., Laguarda-Miró, N., \& Fito, P. (2016b). Microwaves-assisted alkali pretreatment for enhancing pineapple waste saccharification. Bioresources, 11(3), 6518-6531. Gautam. S.S., Mishra, S.K., Dash, V., Goyal, A.K., \& Rath, G. (2010). Comparative study of extraction, purification and estimation of bromelain from stem and fruit of pineapple plant. Thai Journal of Pharmaceutical Sciences, 34, 67-76.

Goula, A.M., \& Lazarides, H.N. (2015). Integrated processes can turn industrial food waste into valuable food by-products and/or ingredients: The cases of olive mill and pomegranate wastes. Journal of Food Engineering, 167, 45-50.

Imandi, S.B., Bandaru, V.V.R., Somalanka, S.R., Bandaru, S.R., \& Garapati, H.R. (2008). Application of statistical experimental designs for the optimization of medium constituents for the production of citric acid from pineapple waste. Bioresource Technology, 99(10), 4445-4450. 
Karam, M.C., Petit, J., Zimmer, D., Djantou E.B., \& Scher, J. (2016). Effects of drying and grinding in production of fruit and vegetable powders: A review. Journal of Food Engineering, 188, 32-49.

Ketnawa, S., Chaiwut, P., \& Rawdkuen, S. (2012). Pineapple wastes: A potential source for bromelain extraction. Food and Bioproducts Processing, 90(3):385-391.

Krishnan, A.V., \& Gokulakrishnan, M. (2015). Extraction, Purification of Bromelain from Pineapple and Determination of Its Effect on Bacteria Causing Periodontitis. International Journal of Pharmaceutical Sciences and Research, 6(12), 5284-5294.

Kumar, D., Jainb, V.K. Shankerb, G., \& Srivastava, A. (2003). Utilisation of fruits waste for citric acid production by solid state fermentation. Process Biochemistry, 38(12), 1725-1729.

Limayem, A., \& Ricke, S.C. (2012). Lignocellulosic biomass for bioethanol production: Current perspectives, potential issues and future prospects. Progress in Energy and Combustion Science, 38(4), 449-467.

Lowry O.H., Rosebrough N.J., Farr A.L., \& Randall R.J. (1951). Journal of Biological Chemistry, 193, 265-275.

Lozano-de-Gonzalez, P.G., Barrett, D.M., Wrolstad, R.E., \& Durst, R.W. (1993). Enzymatic browning inhibited in fresh and dried apple rings by pineapple juice. Journal of Food Science, 58, 399-404.

Moodie, P. (2001). Gelatin digestion unit analytical method. Enzyme Development Corporation, New York.

Nigam, J.N. (2000). Continuous ethanol production from pineapple cannery waste. Journal of Biotechnology. 80(2), 189-193.

Oreopoulou, V. \& Russ, W. (2007). Utilization of By-Products and Treatment of Waste in the Food Industry. Springer.

Owen, P. (1991). Fermentation biotechnology. Ed. John Wiley \& Sons Ltd.

Ratti, C. (2013). Freeze drying for food powder production. In B. Bhandari, N. Bansal., M. Zhang, \& P. Shcuck. (Ed.), Handbook of Food Powders (pp. 57-84). Cambridge, UK: Woodhead Publishing.

Roda, A., De Faveri, D.M., Giacosa, S., Dordori, R., \& Lambri, M. (2016). Effect of pretreatments on the saccharification of pineapple waste as a potential source for vinegar production. Journal of Cleaner Production, 112(5), 4477-4484.

Sánchez, J.O. \& Cardona, C.A. (2008). Trends in biotechnological production of fuel ethanol from different feedstocks. Bioresource Technology, 99(3): 5270-5295. 
Saxena, A., Tripathi, B.P., Kumar, M., \& Shahi, V.K. (2009). Membrane-based techniques for the separation and purification of proteins: An overview. Advances in Colloid and Interface Science, 145(1-2), 1-22.

Schieber, A., Stintzing, F.C., \& Carle, R. (2001). By-products of plant food processing as a source of functional compounds-recent development. Trends Food Science and Technology, 12:401-413.

Tanaka, K., Hilary, Z.D., \& Ishizaki, A. (1999). Investigation of the utility of pineapple juice and pineapple waste material as low-cost substrate for ethanol fermentation by Zymomonas mobilis. Journal of Bioscience and Bioengineering, 87, 5, 642-646. 


\section{FIGURE CAPTIONS}

Figure 1. Interaction plot of the ANOVA (95\% confidence interval). Mean and LSD intervals for ethanol percentage (\%) at $72 \mathrm{~h}$ of fermentation. Factors $\mathrm{pH}(4,5,6)$ and yeast (A: Sacharomyces bayanus CECT 1926; B: Sacharomyces cerevisiae CECT 11020; C: Sacharomyces cerevisiae CECT 1319).

Figure 2. Evolution of Colony Forming Units (CFU), $\mathrm{pH}$ and Total Soluble Solids (Brix degrees) during direct fermentation of the liquor (DF), consecutive saccharification and fermentation (CSF), and simultaneous saccharification and fermentation (SSF) processes. The amount of ethanol yielded (\% v/v) is given in brackets.

Figure 3. Particle size distribution (volume, \%) in the pressed liquor (A: green line) and centrifuged liquor (B: red line). Table: Particle size (d: equivalent diameter, $\mu \mathrm{m})$ in percentiles $0.1,0.5$ and 0.9 for non-centrifuged and centrifuged sample.

Figure 4. Effect of downstream processes on protein concentration determined by the Lowry method.

Figure 5. Proposed integrated processes for pineapple waste valorization.

\section{TABLE CAPTIONS}

Table 1. Physicochemical characteristics of pineapple waste (core and peel). Mean and

Table 2. Comparison among direct fermentation (DF), consecutive saccharification and fermentation (CSF) and simultaneous saccharification and fermentation (SSF) processes. Fermentable sugars (sum of glucose, fructose and sucrose obtained by ion chromatography) and ethanol yield (gethanol/gglucose).

Table 3. Parameters registered before and after fermentation of pineapple waste liquor and permeate obtained by ultrafiltration. Colony Forming Units (CFU) before and after fermentation, Total Soluble Solids (TSS) before and after fermentation, fermentable sugars at the end of fermentation and ethanol produced. 